\title{
La Ley de Amontons y las indagaciones sobre el aire en la Academia de Ciencias de París $(1699-1710)^{1}$
}

\author{
MANUEl SELlÉs GARCíA
}

A José Sala Catalá, in memoriam

\section{RESUMEN}

Casi un siglo y medio separa la formulación de las leyes de los gases ideales enunciadas por R. Boyle y J. L. Gay-Lussac. De hecho, las leyes de Gay-Lussac fueron anticipadas, para el caso del aire, por F. Haubskee y G. Amontons en la primera década del setecientos. En el artículo se examinan los resultados de Amontons en el contexto de las indagaciones sobre el aire llevadas a cabo en la Academia de Ciencias de París.

\section{ABSTRACT}

About a century and a half separates the formulation of the laws of ideal gases stated by R. Boyle and J. L. Gay-Lussac. In fact, GayLussac's laws for the air were anticipated by F. Haubskee and G. Amontons in the first decade of eighteenth century. This paper examines Amontons's results against the context of the investigations carried out on the air in the Paris Academy of Sciences.

1 Este trabajo se enmarca dentro del proyecto de investigación DGICYT PB 89-200. 


\section{Introducción}

En 1661, Robert Boyle halló la primera ley de la física del aire: encontró que (siendo constante la temperatura) su fuerza de resorte es proporcional a su densidad. Por "fuerza de resorte» del aire se entendía entonces la resistencia de éste a la compresión (la propiedad que hoy se denomina elasticidad) ${ }^{2}$. La ley de Boyle, posiblemente redescubierta algunos años después por el francés Edme Mariotte, ha pasado triunfalmente a la historia y a los manuales de física ${ }^{3}$. Junto con la ley que publicaría Gay-Lussac a principios del ochocientos, casi siglo y medio más tarde, se emplea en estos manuales para la deducción de la ecuación de estado de los gases ideales.

Gay-Lussac estableció la proporcionalidad entre las variaciones de volumen y de temperatura, para una muestra dada, a presión constante, y determinó el coeficiente de dilatación; a esta ley se le conoce a veces como ley de Charles pues, tal como menciona en su trabajo el mismo Gay-Lussac, la ley fue descubierta, aunque no hecha pública, por Jacques-Alexander-César Charles alrededor de $1787^{4}$.

Parece un tanto sorprente que más de un siglo separe la formulación de dos leyes básicas del comportamiento de los gases perfectos, que el aire cumple en condiciones ordinarias de presión y temperatura. De hecho, no es así. La ley de Charles y Gay-Lussac tuvo su precedente para el aire en 1708; Francis Haubskee, en las Philosophical Transactions de la Royal Society, exponía un experimento que mostraba para el aire la proporcionalidad directa entre volumen y temperatura ${ }^{5}$. Como este precedente lo pasó por alto Gay-Lussac,

${ }^{2}$ Las investigaciones de Boyle se pueden ver en Solís, C. (1985), Robert Boyle: Física, química y filosofía mecánica, Madrid: Alianza. Los acontecimientos que condujeron a la formulación de la ley se encuentran detallados en WEBSTER, C. (1965), "The Discovery of Boyle's Law and the Concept of Elasticity of Air in the Seventeenth Century», Arch. Hist. Exac. Sci., 2, 441-502.

${ }^{3}$ En verdad, un tanto alterada. Hoy en día se enuncia diciendo que, a temperatura constante, el volumen de una muestra de gas es inversamente proporcional a la presión. Lo que formuló Boyle para el aire es una proporcionalidad directa entre la presión y la densidad.

${ }^{4}$ GAY-LuSSAC, J. L. (1802), "Recherches sur la dilatation des gaz et des vapeurs, lues à l'Institut national, le 11 pluviôse an 10", Annales de Chimie, (1) 43, 137-175.

${ }^{5}$ Haubskee empleó un tubo de vidrio doblado en $\mathrm{L}$, en el que introdujo una porción de mercurio, cerrando su extremo horizontal. Sumergió esta parte horizontal del tubo en agua caliente y luego, mientras se iba enfriando, observó el descenso de la porción de mercurio en la rama vertical del tubo a medida que se contraía el aire que la sustentaba. Halló que, por cada diez grados de descenso de la escala de su termómetro, el mercurio descendía regularmente 0,1 pulgadas. Durante todo el experimento la presión atmosférica se mantuvo constante. HAUBSKEE, F. (1708), «An Account of an Experiment touching the different Densities of the Air, from the greatest Natural Heat, to the greatest Natural Cold in this Climate», Phil. Trans., 26, $\mathrm{n}^{\circ} 315,93-96$. 
no se menciona en ninguna parte. Casi igualmente desconocido es el descubrimiento que publicaría en las Mémoires de la Academia de Ciencias francesa en 1702 el francés Guillaume Amontons: descubrió que, cuanto mayor es el peso de que está cargado el aire, a igualdad de volumen, más aumenta su resorte por un mismo grado de calor. $\mathrm{O}$, dicho en términos más actuales, que dado un incremento de temperatura, el correspondiente aumento de presión, a volumen constante, es directamente proporcional a la densidad ${ }^{6}$. Aunque la contribución de Amontons no ha pasado desapercibida a los historiadores ${ }^{7}$, suele aparecer en los manuales de física como "segunda ley de Gay-Lussac» o, cuanto más, como «una tercera ley que no tiene ningún nombre especial» 8 .

Es sabida la escasa vocación histórica de los manuales de física, cuyo objetivo, muy otro, es la presentación sistemática del cuerpo central de conocimientos de una disciplina. El baconianismo imperante en la Royal Society puede ayudar a explicar que la ley descubierta por Haubskee, expuesta en tres escuetas páginas, no tuviese repercusiones. Aparte de que Haubskee no alcanzó la fama de Boyle y de que, en esa época, no parecía haber nadie en la Royal Society particularmente interesado en los estudios sobre el aire. Sin embargo en Francia, donde todavía se sigue vinculando el nombre de Mariotte a la ley de Boyle, el descubrimiento de Amontons se saludó como una nueva propiedad del aire, y la comparabilidad de sus termómetros de aire basados en tal propiedad fue objeto de amplios debates. El mismo Gay-Lussac, quien menciona a Charles en su trabajo tan sólo de pasada, dedica varias páginas a comentar los resultados de Amontons. En tales circunstancias puede resultar un tanto extraño que su descubrimiento no pasase, como en el caso de Mariotte, a recibir la consideración de ley.

Los motivos de esta postergación son, sin duda, muy diversos. Pero, a mi parecer, ninguno fue tan decisivo como la misma condición de las investigaciones francesas sobre el aire en los años inmediatamente posteriores al des-

\footnotetext{
${ }^{6}$ Como se ha dicho el aire, en condiciones más o menos normales de presión y temperatura, cumple la ecuación de estado de los gases ideales o perfectos, que sé puede escribir como $P=\rho R_{a} T$, en donde $P$ es la presión, $\rho$ la densidad, $T$ la temperatura absoluta, y $R_{a}$ una constante particular del gas referida a la unidad de masa del mismo. Cuando $T=$ cte., se ve que $\Delta P \propto \Delta \rho$, que es la ley de Boyle; siendo $P=$ cte., se ve que $\rho T=$ cte., esto es, que $T \propto V$, siendo $V$ el volumen de una masa dada de gas, que es la ley de Haubskee (la de Gay Lussac lo generaliza a todos los gases, cualquiera que sea su densidad y la cantidad de agua que tienen en disolución, y a todos los vapores). Finalmente, siendo $\rho=$ cte., se ve que $\Delta P \propto \Delta T$ y que, dado un $\Delta T, \Delta P \propto \rho$, que es la ley descubierta por Amontons.

7 Se la conoce sobre todo gracias a los comentarios de Middleton. Véase MiddLeton, W. E. K. (1966), A History of the Thermometer and Its Use in Meteorology, Baltimore, Maryland: The Johns Hopkins Press, pp. 105-106.

8 Como ejemplo de lo primero, véase Aguilar PERIS, J. (1970); Termodinámica y mecánica estadística, Valencià, ( $3^{a}$ edición), p. 71. Como ejemplo de lo segundo, FERnándEZ RAÑADA, A. (ed) (1993), Física básica, vol. 1, Madrid: Alianza, p. 345.
} 
cubrimiento de Amontons. En las páginas que siguen expongo las circunstancias que condujeron a Amontons a la formulación de su ley en el contexto de estas indagaciones publicadas por la Academia de Ciencias de París entre 1699 y 1710 . Estas, aparentemente abocadas a un callejón sin salida, no sólo empañaron los resultados de Amontons, sino que también pusieron en entredicho la ley de Boyle-Mariotte; y si bien, por otro lado, condujeron a la comprensión cabal de la gran influencia de la temperatura y de la humedad sobre la fuerza elástica del aire, fueron abandonadas, un tanto inexplicablemente, en el momento en que parecía haberse salvado el escollo principal.

\section{La acción del fuego}

Cuando Otto von Guericke puso de manifiesto el gran poder de la presión atmosférica con el famoso experimento de los hemisferios de Magdeburgo y otros por el estilo, se propusieron algunas máquinas basadas en este fenómeno. La idea, básicamente, consistía en lograr el vacío en el interior de un cilindro cerrado por un pistón, de modo que la presión de la atmósfera proporcionase una fuerza motriz al empujarlo hasta el fondo del cilindro9. En la línea de estas tentativas, Guillaume Amontons sugirió, en una memoria presentada a la Academia de Ciencias de París en 1699, una máquina cuya fuerza motriz venía suministrada por la presión de aire fuertemente dilatado por el calor ${ }^{10}$. Con el fin de mostrar la viabilidad de la máquina, en la memoria se presentaba una experiencia sobre el aumento de la fuerza de resorte del aire cuando se elevaba su temperatura desde la del ambiente hasta la de ebullición del agua ${ }^{11}$.

En el experimento, Amontons dispuso tres tubos de vidrio, de la misma longitud y de un diámetro interior de alrededor de media línea, curvados en $\mathrm{U}$; los

\footnotetext{
9 En 1680, Cristiaan Huygens propuso emplear la combustión de la pólvora para la fase de expansión; el exceso de los residuos de la combustión y el aire caliente salían por unas válvulas, y al enfriarse el cilindro se creaba en éste un vacío parcial. Diez años después, su ayudante Denis Papin sugirió el uso de agua: al ser calentada ésta en el fondo del cilindro, y evaporarse, empujaba al pistón, lográndose el vacío al condensarse el vapor por enfriamiento. El primer diseño utilizable de este tipo, el "amigo del minero" de Thomas Savery, se patentó en 1698. Se trata de "máquinas de aire» y no "de vapor", pues esta última denominación se reserva para aquéllas que emplean como fuerza motriz, no la presión atmosférica, sino la fuerza expansiva del vapor generado a altas temperaturas.

10 Amontons, G. (1699), «Moyen de substituer commodement l'action du feu, a la force des hommes et des chevaux pour mouvoir les machines", Mém. Acad. Sci., 112-126.

11 Si bien la propuesta de Amontons era la de calentar directamente el recipiente que contenía el aire a temperaturas mayores de las que se obtendrían sumergiéndolo en agua hirviendo.
} 


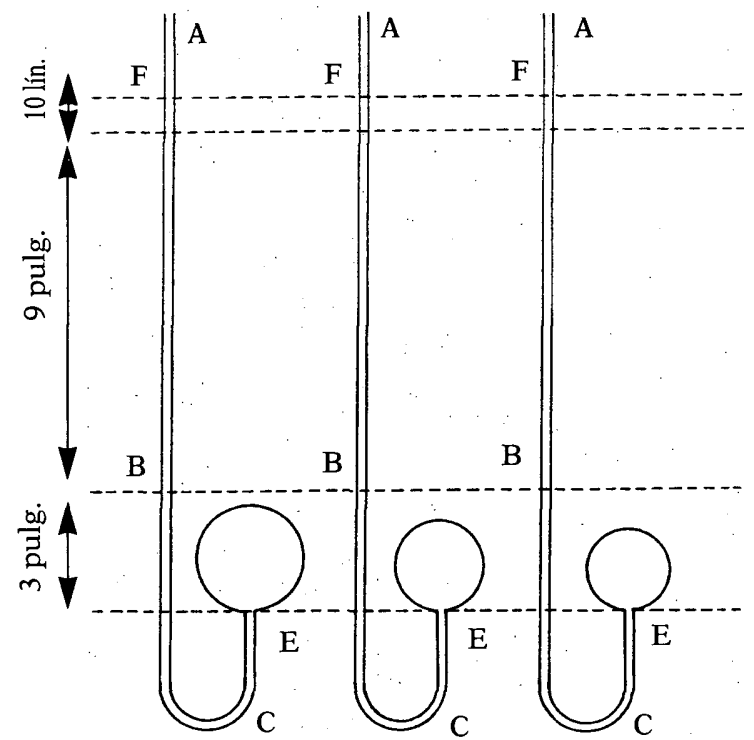

Figura 1

tubos, como muestra la fig. 1, estaban abiertos por el extremo más largo, hallándose rematados en el otro por bolas huecas de vidrio cuyas capacidades estaban entre sí como los números 1,2 y $3^{12}$. Llenó los tubos con mercurio, de modo que su nivel en las ramas cortas quedase en la entrada $\mathrm{E}$ de las bolas, y en los tubos abiertos en B, tres pulgadas más arriba. Así que el aire encerrado en las bolas, respecto del ambiente, estaba sometido a una sobrepresión de tres pulgadas de mercurio.

A continuación introdujo las tres bolas en un recipiente con agua y puso éste a calentar. Observó que, a medida que el aire de las bolas se calentaba, dilatándose, el mercurio ascendía a la vez en los tres tubos, haciéndolo a la misma tasa. Cuando el agua del recipiente llegó a la ebullición, el mercurio, que había subido en los tubos 9 pulg. y 10 lín., cesó de ascender. Amontons extrajo de aquí cinco consecuencias:

1. Que el agua en ebullición mantiene constante su temperatura; se trata de un descubrimiento que aprovechará un poco más adelante para proponer esta temperatura como punto fijo en el calibrado de termómetros.

12 Las unidades de longitud empleadas en la Francia de la época eran como sigue: 1 toesa $=6$ pies; 1 pie $=12$ pulgadas; 1 pulgada=12 líneas; 1 línea=12 puntos. Como 1 toesa $=1,950$ metros, resulta que 1 línea equivale a 2,257 milímetros. 
2. Que masas desiguales de aire aumentan igualmente la fuerza de su resorte (su presión) por grados de calor iguales (por el mismo incremento de temperatura).

3. Que el calor del agua hirviendo no aumenta este resorte más que hasta hacer sostener al aire un sobrepeso sobre el atmosférico de alrededor de 10 pulg. de mercurio. A las 9 pulg. 10 lín. de subida obtenidas en el experimento, añade aquí otras 2 lín. para compensar aproximadamente la pérdida de resorte por la dilatación del aire de las bolas, que se ha extendido hasta ocupar el volumen que ha dejado libre el mercurio al ascender por el tubo.

4. Aplica ahora la ley de Mariotte para concluir que, sometido a una elevación de temperatura desde la del ambiente hasta la del agua hirviendo, y actuando sólo la presión de la atmósfera, el aumento de volumen que sufriría el aire correspondería al de un tercio de su volumen inicial.

5. Que, si el aire no puede dilatarse hasta aumentar su volumen en la tercera parte, para distintos volúmenes de aire las presiones correspondientes serán a la atmosférica como la razón inversa de dichos volúmenes.

Habiendo estudiado así el aumento del resorte del aire con la elevación de la temperatura, pasa a estudiar el efecto contrario, sumergiendo las bolas en lo que denomina agua fría, a una temperatura más o menos la del ambiente ${ }^{13}$. Observó que el mercurio descendió 1 lín. en la bola mayor, 2 en la mediana y 3 en la menor. De esto concluyó que el aire disminuye su resorte por el frío en proporción inversa a su volumen. Luego sacó los tubos del agua, y mientras ésta se evaporaba del exterior de las bolas, observó que el mercurio seguía descendiendo: llegó a 1 lín. menos en la bola menor, 2 en la mediana y 3 en la mayor, recuperando luego poco a poco su nivel inicial en B a medida que las bolas se secaban. La conclusión que extrajo fue que «el agua que está a punto de evaporarse» disminuye más la fuerza de resorte del aire que cuando este agua se encuentra en cantidad lo bastante grande como para rodearlo por todas partes, y que esta segunda disminución de la fuerza de resorte se produce también en proporción al volumen ${ }^{14}$.

\section{La nueva propiedad del aire}

Amontons, en su memoria de 1699 , se mostraba interesado únicamente por la cuantía del aumento del resorte del aire con el calor, que halló, en los

\footnotetext{
${ }^{13}$ La temperatura del "agua del grifo", como diríamos hoy.

${ }^{14}$ Expone también una experiencia similar con espíritu de vino. Estos experimentos anticipan de alguna manera las investigaciones de Joseph Black a mediados del siglo; pero Amontons, que evidentemente no estaba interesado en el fenómeno, se limita aquí a constatarlo de pasada.
} 
márgenes de temperatura vistos, de unas modestas 10 pulg. de mercurio. Tres años después, en 1702, presentó una nueva memoria en la que, ya olvidado el "molino de fuego", proclamaba el hallazgo de una nueva propiedad del aire ${ }^{15}$. Amontons, extendiendo sus experimentos, había encontrado que ese aumento de presión de 10 pulg. de mercurio podía crecer en proporción directa a la densidad de la masa de aire. Dicho en sus propios términos: «un mismo grado de calor, por pequeño que sea, puede aumentar siempre cada vez más la fuerza de resorte del aire, si este aire está siempre cargado con un peso cada vez más grande». Y como ya encontró que masas desiguales de aire aumentan igualmente su fuerza de resorte por grados de calor iguales, concluyó también que «una porción de aire muy pequeña, por pequeña que sea, puede adquirir una fuerza de resorte cada vez más y más grande por un grado de calor muy pequeño, si esta pequeña porción está siempre cada vez más cargada» 16 . Lo que, en términos más actuales, quiere decir que el incremento de presión producido por un incremento de temperatura en una masa de aire es directamente proporcional a su densidad ${ }^{17}$. Tal como anunciará este resultado Fontenelle, el Secretario Perpetuo de la Academia, Amontons «ha encontrado una propiedad del aire nueva, singular, y que a primera vista puede parecer sorprendente» 18 .

La justificación teórica que da Amontons de este resultado responde al marco mecanicista imperante. Según dice, las partes del fuego se hallan en un movimiento continuo y violento, y sólo se puede concebir el calentamiento que imprimen a las partes de los cuerpos más sólidos suponiendo que, por el esfuerzo que hacen para penetrarlas, les comunican parte de este movimiento; ésta era la teoría del calor aceptada mayoritariamente en la época. El resultado del experimento se explica porque las partes del aire que contiene cada una de las bolas se encuentran a la misma distancia entre sí (es decir, las tres bolas contienen aire con la misma densidad), y las partes del fuego que las ponen en movimiento «son las mismas paralelamente» (las tres bolas sufren la misma elevación de temperatura): de modo que no pueden comunicar más movimiento a unas que a otras, y por ello tendrán que adquirir la misma fuerza de resorte.

\footnotetext{
15 Amontons, G. (1702), «Discours sur quelques propietés de l'air, et le moyen d'en connoître la temperature dans tous les climats de la terre», Mém. Acad. Sci., 155-174.

16 Ibid., p. 156.

17 MidDlETon (1966), p. 107, lleva más lejos esta «traducción» a términos actuales. Según dice, el resultado es que la forma de la relación entre la temperatura y la presión es independiente de la presión inicial. Una conclusión que ya presentó Gay-Lussac. Vid. GAY-LuSSAC (1802), 145.

${ }^{18}$ Fontenelle, B. B. (1702), «Sur une nouvelle propieté de l'air, et une nouvelle construction de Thermomètre», Hist. Acad. Sci., 1-8; p. 3.
} 
Si, ahora, las masas están más cargadas, hay más partes de aire en el mismo espacio, y las partes del fuego no pueden insinuarse entre ellas sin separarlas; pero como estas masas no pueden aumentar su volumen, aumentan su fuerza de resorte.

Amontons no recurre aquí al entonces ya clásico modelo que compara a las partes del aire con una especie de laminillas elásticas enrolladas, pero sí lo hace Fontenelle en el resumen que redacta para la Histoire ${ }^{19}$. Dado que las partes del fuego (infinidad de pequeñas partículas muy agitadas) se alojan en los intersticios de estas laminillas, y sobre todo que se mueven con gran violencia, las desenrollan en lo posible cuando la masa de aire puede aumentar su volumen, pero si esto no es posible, como tienden a abrir las espiras, aumentan la fuerza de resorte ${ }^{20}$.

El modelo servía igualmente bien para explicar por qué se mantiene constante la temperatura del agua hirviendo ${ }^{21}$. Según W. Homberg, destacado químico mecanicista y miembro de la Academia, un cuerpo está caliente porque se halla penetrado en todos los sentidos por la materia de la llama o de la luz, una infinidad de pequeños dardos "très-picans" que comunican las impresiones del calor a los cuerpos a los que golpean. Cuando se pone a calentar un recipiente con agua, la llama, empujada de abajo hacia arriba por el peso del aire, tiende a abrirse camino en el agua según esta dirección. Al principio encuentra dificultades, pues los caminos no están abiertos, pero cuando los abre, y el agua hierve todo lo que puede hervir, la materia de la llama ha alcanzado su máximo efecto: ni puede abrir más los caminos, ni abrirlos en mayor cantidad ${ }^{22}$. Todo parecía estar bastante claro.

Aunque, de mucha mayor trascendencia que todas estas especulaciones, incluso cabe decir que por encima del mismo descubrimiento de esa «nueva propiedad del aire» que le servía de fundamento, estaba su aplicación a la

$19 \mathrm{Ibid}$. Un modelo que se difundió desde que J. Pecquet lo expusiera en sus Experimenta nova anatomica, (París, 1661). Véase WeBSTER (1965).

${ }^{20} \mathrm{La}$ explicación de la ley de Boyle, con este modelo, es trivial. Si, siguiendo a Fontenelle y a otros muchos, el aire se concibe "compuesto de una infinidad de pequeñas láminas de resorte, bien espirales, bien de cualquier otra figura que se juzgue más conveniente», estas láminas se cierran, y sus extremidades se aproximan tanto más cuanto mayor es la carga que sufre el aire; en tal situación, las láminas no sólo ocupan menos espacio, sino que su tensión elástica es mayor. Véase Solís (1985), 91 ss.

${ }^{21}$ Como se ve, una característica sobresaliente de estos modelos mecanicistas era que podían explicar cualquier cosa, a cambio de no predecir nada.

${ }^{22}$ Fontenelle, B. B. (1703), "Diverses observations de physique générale», Hist. Acad. Sci., Secs. XII y XIII, pp. 24-25 y 25-26. 
termometría. En 1695, Amontons había propuesto un modelo de termómetro de aire que empleaba tres líquidos ${ }^{23}$. Ahora sugería un solo líquido, el mercurio, en un termómetro de construcción semejante a uno de los tubos de la fig. 1. Su idea era usar la temperatura de ebullición del agua como punto fijo, de modo que hallándose sumergido el bulbo en agua hirviendo, el aire que contenía estuviese sometido a una sobrepresión de 45 pulg. de mercurio, cuando el barómetro indicase una presión atmosférica de $28 \mathrm{pulg}^{24}$. De ese modo podría disponerse de un termómetro «universal» que permitiese la comparabilidad de las lecturas efectuadas en distintos lugares (posiblemente empleándolo como patrón para calibrar los entonces comunes termómetros de espíritu de vino).

Anticipando acontecimientos, cabe decir que las aspiraciones termométricas de Amontons se verían frustradas desde dos frentes distintos: por una parte, como descubriría Fahrenheit años después, la temperatura de ebullición del agua no es constante, sino que varía con la presión (llegando a proponer un modelo de barómetro basado en esto $)^{25}$. Por otra, y como se verá más adelante, se descubriría que el grado de humedad presente en el aire contenido en el bulbo iba a destruir las pretensiones de comparabilidad entre termómetros de aire fabricados en distintos momentos o lugares; pero antes conviene atender a algunos problemas que se suscitaron en torno a la ley de Boyle-Mariotte.

\section{Los límites de las leyes}

Desde que se formulara la imagen de la atmósfera como un «mar de aire», se planteó la cuestión de cuál era su límite superior. La ley de Boyle, al relacionar las presiones con las densidades, proveía de un medio teórico de extrapolar la variación de la presión con la altura, y Robert Hooke, Edme Mariotte y Edmond Halley dedujeron las primeras reglas para hacerlo, buscando determinar asimismo dónde terminaba la atmósfera. Tal límite, de acuerdo con la forma matemática de la ley, no existía: el aire debía rarificarse cada vez más, extendiéndose infinitamente hacia los abismos del espacio. Así que, si se quería obtener una cifra para la altura de la atmósfera, había que dejar de lado los estratos superiores, más tenues, a partir de alguno determinado. Edmond Halley, en 1686, percibiendo la analogía de la forma de la ley de Boyle con una hipérbola, propuso una fórmula hipsométrica que, salvando la

\footnotetext{
23 Amontons, G. (1695), Remarques et expériences physiques sur la construction d'une nouvelle clepsidre, sur les barometres, termometres et higrometres, París, pp. 146-57.

24 AMONTONS (1702), Middleton (1966), pp. 105-08.

25 Fahrenheit, D. G. (1724), "Barometri novi descriptio», Phil. Trans., 33, 179-80.
} 
corrección por los efectos de la temperatura, que Halley no introdujo, no ha perdido actualidad. Halley calculó las expansiones del aire a distintas alturas, hallando que, a 41 millas, el aire ocupa un volumen 3. 000 veces superior al que ocupa al nivel del suelo y, a 53 millas, 30. 000. Pero no creía que la fuerza de resorte del aire pudiese actuar a estas expansiones, y fijó la altura de la atmósfera en 45 millas, un valor que le coincidía muy bien con el determinado por el método de los crepúsculos ${ }^{26}$. La razón con que apoyaba la existencia de un límite a la expansión era que, fuese cual fuere la textura de las partes del aire, éstas deberían, como en el caso de la lana y otros cuerpos compresibles cuando se hallan libres de toda carga, poseer una magnitud determinada propia de ese estado natural, en el que están libres de todo tipo de presión. La analogía con la lana o cuerpos similares era ya vieja, y el argumento ya se había esgrimido antes.

El límite inferior parecía algo más fácil de establecer. Se suponía que, puesto que las partes del aire debían tener algún tamaño, el límite de la compresión se alcanzaría cuando dichas partes llegasen a entrar en contacto (caso en el cual el aire se tornaría incompresible y se comportaría como un líquido $)^{27}$. Halley aludía a las experiencias realizadas en la Academia del Cimento que pusieron de manifiesto la incompresibilidad del agua y, dado que había adoptado para la gravedad específica del agua un valor 800 veces mayor que el del aire en la superficie terrestre, consideraba que dicho aire, comprimido hasta un volumen 800 veces menor, perdería su propiedad elástica ${ }^{28}$.

Por su parte Amontons, en desacuerdo con Halley, no creía que existiese fuerza alguna capaz de extraer por completo las partículas ígneas que penetran el aire y cuyo movimiento consideraba responsable de su fuerza de resorte $^{29}$. O, lo que es lo mismo, pensaba que prácticamente no había límite

\footnotetext{
${ }^{26}$ El crepúsculo es la iluminación de la atmósfera por los rayos del Sol cuando éste se encuentra por debajo del horizonte. Este termina cuando el Sol se encuentra a $18^{\circ}$ por debajo, lo que, unido al conocimiento del semidiámetro terrestre y los efectos de la refracción atmosférica, permite determinar la altura buscada. Esta altura es aquélla a la cual no existe aire capaz de reflejar apreciablemente hacia la superficie terrestre los rayos del Sol.

$27 \mathrm{Si}$ se adopta el modelo que concibe a las partes del aire como laminillas con resorte, el límite superior se alcanzaría cuando estas laminillas se hallasen conpletamente extendidas (por lo que su fuerza de resorte sería nula), y el inferior cuando las dos extremidades de las láminas llegasen a tocarse (por lo que su fuerza de resorte sería máxima)

${ }^{28}$ HaLley, E. (1686), "A Discourse of the Rule of the decrease of the hight of the Mercury in the Barometer, according as places are Elevated above the Surface of the Earth, with an attempt to discover the true reason of the Rising and Falling of the Mercury, upon change of Weather», Phil. Trans, 16, 104-116. En términos anacrónicos, lo que está considerando Halley es que el aire no es un gas del todo «ideal», habida cuenta del tamaño finito de sus partículas.

29 Como hace notar Middleton (1966), p. 110, esta línea de razonamiento (proporcionalidad de la elasticidad a la cantidad de calor en el aire), que más tarde compartiría Johann Heinrich Lambert, conduciría a este último a una escala "absoluta» de temperatu-
} 


\section{LA LEY DE AMONTONS Y LAS INDAGACIONES SOBRE EL AIRE}

a su capacidad de condensación, pues éste resultaba inalcanzable. Efectuó cálculos sobre las densidades que podría alcanzar el aire dentro de la corteza terrestre y obtuvo unas cifras enormes (a 43. 528 toesas de profundidad, que representaba sólo 1/74 parte del radio terrestre, tendría la densidad del oro), que suponían aumentos casi increibles de la fuerza de resorte del aire al elevarse sólo un poco la temperatura. Sin embargo, cuanto mayor fuese la densidad del aire, menos espacio libre quedaría entre sus partes para las partículas ígneas, y menos calor podría penetrar en el interior de la Tierra desde los orbes superiores. La idea de un fuego central quedaría, según esto, en entredicho ${ }^{30}$.

Estas limitaciones en la compresión y rarefacción del aire, por evidentes que pudiesen parecer, venían a empañar la exactitud de la ley en todo el rango de presiones, una exactitud a la que seguramente muchos, más influídos por Descartes que por Bacon, hubiesen deseado que se plegase de buen grado la naturaleza. Así se manifestó el Secretario Perpetuo de la Academia, en sus comentarios en la Histoire para 1716 sobre un trabajo de Varignon en el que se deducía una fórmula hipsométrica general que englobaba todos los casos posibles de variación del peso del aire con la altura ${ }^{31}$. Las dos hipótesis empleadas a la hora de determinar la variación de la densidad del aire habían sido la ley de Boyle-Mariotte y la suposición de que su peso era constante con la altura; y con ello se concluía que la altura de la atmósfera era infinita. Sin embargo, manifestaba Fontenelle, si se concibe la densidad infinita «es decir, todas las partes propias del aire tan próximas las unas de las otras como jamás lo pueden estar», ningún aumento del peso compresor seguirá teniendo efecto, y por ello mismo se ve que la densidad del aire no puede ser siempre proporcional al peso de que está cargado. Asimismo, pro-

ras con un "cero absoluto" de calor obtenido por extrapolación a una presión nula. Middleton afirma que esta línea de razonamiento conlleva «la suposición totalmente metafísica de una relación lineal entre presión y cantidad de calor». Pero habría que hacer notar que esta relación "metafísica» había sido puesta de manifiesto por Amontons, para un cierto intervalo de temperaturas, en su memoria de 1699: concluía allí, como se ha visto, que masas desiguales de aire (pero con la misma densidad) aumentan igualmente la fuerza de su resorte por grados de calor iguales. Pero, además, ahora Amontons está afirmando que a muy bajas temperaturas esa relación no es lineal.

30 Amontons, G. (1703), "Que les nouvelles expériences que nous avons du poids et du ressort de l'air, nous font connoître qu'un degré de chaleur mediocre, peut réduire l'air dans un état assez violent pour causer seul de tres-grands tremblements et bouleversements sur le Globe terrestre», Mém. Acad. Sci., 101-108.

31 VARIGNON, P. (1716), «Rapports des differentes densités de l'air, ou de toute autre matiere fluide élastique continuë de telle variabilité de pesanteur qu'on voudra, à des hauteurs quelconques; de laquelle matiere élastique les densités causées par la seule gravitation de ses parties superieures sur les inferieures, soient en raison d'une puissance quelconque des poids comprimants», Mém. Acad. Sci., 107-136. 
sigue, Varignon «encuentra que la Geometría aplicada a esta hipótesis se opone en cierto modo, y que uno se ve detenido por inconvenientes geométricos que hacen sentir que no se está en una buena vía» ${ }^{32}$.

Puede pensarse que Fontenelle está hilando muy fino, pero lo cierto es al parecer que nadie estaba dispuesto a aceptar una atmósfera ilimitada. Brook Taylor, en su Methodus incrementorum directa et inversa (Londres, 1715), obtuvo la fórmula de la variación de la densidad con la altura desde el supuesto newtoniano del decrecimiento de la fuerza de gravedad con la distancia al centro de la Tierra. Enfrentado a la consecuencia de que la ley de Boyle conduce inevitablemente a una densidad finita a todas las alturas, sugiere que las fuerzas naturales no se extienden al infinito, y que resulta más probable que la fuerza elástica del aire, a partir de un determinado grado de rarefacción, disminuya continuamente ${ }^{33}$.

Todo esto, en fin, no eran sino especulaciones, pues el conocimiento empírico sólo se había obtenido a alturas muy pequeñas y a compresiones poco elevadas, y dentro de ese margen parecía demostrado que la ley de Boyle-Mariotte se cumplía con una notable aproximación. Sin embargo, la variación de la densidad o la fuerza de resorte del aire con la altura y el límite de la atmósfera no eran sólo cuestiones cuya resolución se buscase para satisfacer la curiosidad del filósofo natural. En la época, tenían una incidencia crucial en la astronomía y en la cartografía. En la primera, porque la precisión de las observaciones de posición de los astros se había visto notablemente mejorada con la adopción de miras telescópicas, hasta el punto de que la corrección de la refracción había pasado a constituir ahora la limitación más importante a la exactitud que se buscaba en las medidas astronómicas. En la segunda, porque el desarrollo de la hipsometría barométrica prometía un medio de determinación de cotas más preciso que el antiguo método tri-

\footnotetext{
32 Fontenelle, B. B. (1716), "Sur les rapports des densités de l'air», Hist. Acad. Sci., 4044; en p. 43.

33 Citado por Truesdell, C. (1954), «Rational Fluid Mechanics, 1687-1785». Introducción del Editor a Leonhardi Euleri Opera Omnia, II 12, Lausana, p. XVI. Según Truesdell, tras estas frases se esconde una defensa de Newton "característicamente inglesa", pues si la atmósfera de la Tierra se extiende hasta los cuerpos celestes, se pone en entredicho el sistema del mundo calculado a partir de la teoría de movimientos en el vacío. Piénsese, sin embargo, que si la atmósfera se extendiese hasta la esfera de influencia de la Luna, sufriría su atracción gravitatoria, y formaría allí una atmósfera, cuyos efectos refractivos, de ser un tanto notables, se hubiesen puesto de manifiesto en la época, por ejemplo, en las observaciones de ocultaciones de estrellas. Tampoco hay que perder de vista el hecho obvio de que, si bien la atmósfera pudiese resultar ilimitada, la cantidad de aire contenida en ella era finita, y determinada; por ejemplo, Halley señalaba que, si se imagina al aire incompresible, con la misma densidad del agua, la altura de la atmósfera no superaría las 5,1 millas (HALLey (1686), p. 104). No parece, pues, que esto pudiese suponer un rozamiento lo suficientemente notable como para constituir una grave amenaza al sistema del mundo newtoniano.
} 


\section{LA LEY DE AMONTONS Y LAS INDAGACIONES SOBRE EL AIRE}

gonométrico (cuya mayor fuente de incertidumbre, por otra parte, se hallaba en la corrección de la refracción), precisión que, sobre todo, se hacía necesaria a la hora de proceder a la nivelación de las cadenas de triángulos que, surcando un territorio, constituían la urdimbre de su levantamiento geográfico ${ }^{34}$. Desde ambos contextos, pero especialmente desde el segundo, las observaciones parecerán hallarse en desacuerdo con la ley de BoyleMariotte.

\section{El aire de las montañas y el aire del laboratorio}

Durante la mayor parte del siglo XVII, los astrónomos, a falta de cosa mejor, aceptaron el modelo de la refracción de Kepler, que suponía que el rayo de luz sufría una única refracción en una atmósfera de altura muy reducida. El modelo desarrollado por G. D. Cassini a mediados de siglo, descubierta ya la ley de Snell, se mantenía en la misma línea, pues suponía una sola refracción en una atmósfera de densidad uniforme. Pronto, no obstante, se consideró necesaria la obtención de una nueva regla para la corrección de la refracción que reconciliase el valor de la altura de la atmósfera que surgía de este modelo con el obtenido por el método de los crepúsculos ${ }^{35}$, y que atendiese al decremento de la densidad del aire desde la superficie de la Tierra (lo que tornaba en curva la trayectoria de la luz, que en el modelo de una sola refracción resultaba recta). Flamsteed, el astrónomo real inglés, era consciente de ello, y habiendo encontrado serias discordancias en el valor de la refracción cerca del horizonte obtenido por varios astrónomos y por él

\footnotetext{
34 Un vistazo a la obra de Lafuente, A. y Delgado, A. J. (1984), La geometrización de la Tierra (1735-1744), Madrid: CSIC, aclarará perfectamente la no pequeña índole de los problemas que planteaba una operación de este tipo.

$35 \mathrm{Si}$ se supone que la densidad del aire no varía con la altura, el límite superior que se obtiene para la atmósfera es muy bajo. Así, el modelo de G. D. Cassini supone una atmósfera de 2. 000 toesas (unos $4 \mathrm{kms}$., en números redondos), lo que le hace pensar que no es el aire el responsable del fenómeno, sino una "materia refractiva" que se encuentra en la parte baja de la atmósfera, y cuyo límite superior se halla bien definido. El método de los crepúsculos daba resultados que rondaban en torno a los $70 \mathrm{kms}$. (Como se vio, Halley estimó la altura de la atmósfera en 44,4 millas - unos 71,5 kms.-, mientras que La Hire la estimó en 34.585 toesas -unos 67,5 kms.). Un tercer método se basaba en las observaciones de ciertos meteoros ígneos (lo que hoy llamamos bólidos), que entonces se suponían originados por exhalaciones sulfurosas cuya levedad relativa las haría ascender por la atmósfera hasta su parte superior, donde se inflamarían. Montanari, en Bolonia, observó uno de tales meteoros en 1676, y comparando la suya con otras observaciones concluyó, por el método de la paralaje, una altura de 15 leguas francesas (lo que, a 2.200 toesas por legua, da unos $64,5 \mathrm{kms}$.), en un acuerdo sorprendente con los valores anteriores. LA HIRE, P. DE (1713), "Sur la hauteur de l'atmosphere», Mém. Acad. Sçi., 54-66.
} 
mismo, en el otoño de 1694 solicitó a Newton que se ocupase del problema. Newton aceptó el desafío y, en un primer intento, trató de obtener la trayectoria del rayo suponiendo la existencia de una "fuerza refractiva» entre dos estratos contiguos de aire de diferente densidad, fuerza de magnitud proporcional a tal diferencia; esta magnitud resultaba constante en todos los puntos de la atmósfera al suponer que la densidad variaba linealmente con la altura. Esta hipótesis era evidentemente artificial, pues se hallaba en flagrante contradicción con la ley de Boyle, que el mismo Newton había aplicado a la atmósfera terrestre en la Prop. XXII del Libro II de los Principia ${ }^{36}$. De modo que, en un segundo intento, partió de esta constitución de la atmósfera expuesta en los Principia. Esto le condujo a una segunda tabla de refracciones, que Newton envió a Flamsteed en marzo de 1695, y que no sería difundida hasta que fuese publicada por Halley en las Philosophical Transactions de $1721^{37}$. De hecho, los resultados no fueron muy lucidos. Pero lo que aquí nos interesa destacar no es la mayor o menor calidad de las tablas de refracción al uso, sino la percepción de las causas de las disparidades encontradas entre la teoría y la observación. En este sentido, ya Picard, en 1669, había señalado la necesidad de obtener una tabla de refracciones para París atendiendo a las distintas estaciones del año y, en definitiva, al estado del tiempo atmosférico ${ }^{38}$. Newton, asimismo, es bien consciente del importante papel que juega la distribución de temperatura en la atmósfera. En este sentido, considera que el efecto se acumula fundamentalmente en la región más baja de ésta, sometida a las alternancias de calor y frío, mientras que en las regiones superiores, donde predomina el frío, los cambios son menos sensibles $^{39}$. Igualmente Halley, en su memoria de 1686, advirtió acerca de la influencia del calor y del frío, los cuales podían producir desviaciones de su

\footnotetext{
${ }^{36}$ Que enunció así: «Sea la densidad de un fluido cualquiera proporcional a la compresión y sus partes sean atraídas hacia abajo por una gravedad inversamente proporcional a los cuadrados de sus distancias al centro; digo que si las distancias se toman en proporción armónica, las densidades del fluido a esas distancias estarán en progresión geométrica». NEwTON, I. (1687), Principios matemáticos de la filosofía natural. Cito por la trad. de E. Rada, 2 vols., Madrid: Alianza, 1987; vol. 2, p. 491. Como se vio, Halley demostraría poco después que tal proporción se ajustaba a una hipérbola.

37 Las indagaciones de Newton se analizan en Whiteside, D. T. (1980), «Kepler, Newton and Flamsteed on Refraction Through a "Regular Aire" $)$ : the Mathematical and the Practical», Centaurus, 24, 288-315. Véase asimismo Grant, R. (1852), History of Physical Astronomy, Londres. Reimp. en Nueva York y Londres: Johnson Reprint Corp., 1966, pp. 320 ss., donde se recoge la historia dentro de un panorama general del problema de la refracción en la época. También Lafuente, A. y Delgado, A. J. (1984), pp. 173 ss.

38 Fontentele, B. B. (1733), Histoire de l'Académie Royale des Sciences, depuis son établissement en 1666, jusqu'a 1699, París, p. 109.

${ }^{39}$ En una carta a Flamsteed del 24 de octubre de 1694. Citada en Grant (1852), p. 324 .
} 
LA LEY DE AMONTONS Y LAS INDAGACIONES SOBRE EL AIRE

regla; sin embargo, creía que éstas se verían compensadas por los vapores que, elevándose en mayor cantidad cuando el aire estaba rarificado por el calor, contribuirían con su peso a mantener más o menos constante la presión ${ }^{40}$. También Fontenelle, en 1706, subrayó la gran incertidumbre que las condiciones atmosféricas introducían en la corrección de la refracción ${ }^{41}$. De modo que, en definitiva, por los años que nos ocupan los astrónomos parecían ser bien conscientes de que el estado del tiempo atmosférico, y en especial la temperatura, influyen de una manera significativa en la refracción atmosférica, aun cuando todavía no fuesen capaces de cuantificar dicha influencia. Pero, entonces, ¿por qué esos mismos astrónomos, cuando ascendían a las montañas barómetro en mano, parecían reticentes a considerar estos mismos efectos de la temperatura en la presión atmosférica?

Como ya se anticipó, las mediciones hipsométricas arrojaron serias dudas sobre la validez de la ley de Boyle-Mariotte ${ }^{42}$. El problema se planteó a partir de las observaciones efectuadas por J. Cassini y sus colaboradores durante las operaciones de prolongación del meridiano de París en el sur de Francia. Dichas observaciones mostraban que, a medida que aumentaba la altura, la dilatación del aire era mayor que la predicha por la teoría. Así que J. Cassini y G. F. Maraldi confeccionaron una nueva tabla, que se publicó en las Mémoires de la Academia para $1705^{43}$. Naturalmente, la validez de la ley no se podía descartar sin más, y esto condujo a contrastarla de nuevo. Así, J. Cassini por un lado, y Amontons por otro, repitieron las experiencias de Mariotte. El procedimiento consistía en emplear un tubo de vidrio cerrado por un extremo (un tubo de barómetro) que se llenaba con mercurio hasta una determinada altura, tras lo cual el tubo se invertía en la cubeta de mercurio, y se veía cuánto se elevaba este mercurio por la presión atmosférica. Según la ley, los volúmenes inicial (a la presión atmosférica) y final ocupados por la porción de aire que se había dejado en el tubo debían estar en la misma proporción que los pesos, esto es, que la altura del mercurio con el tubo vacío de aire (que señalaba la presión atmosférica) y la diferencia entre ésta y la altura del mercurio cuando el tubo contenía el aire dilatado. Y esto

\footnotetext{
${ }^{40}$ Halley (1686), pp. 108-109. Esta opinión la rectificará en Halley, E. (1720), «Some Remarks on a late Essay of Mr. Cassini, wherein he proposes to find, by observation, the parallax and magnitude of Sirius», Phil. Trans.,31, 1-4.

${ }^{41}$ Fontenelle, B. B. (1706), "Sur les refractions», Hist. Acad. Sci., 101-103.

${ }^{42}$ Sobre el desarrollo de la hipsometría barométrica, véase Feldman, T. S. (1985), «Applied mathematics and the quantification of experimental physics: The example of barometric hypsometry", Hist. Stud. Phys. Sci., 15, 127-197. También Frisinger, H. H. (1974), «Mathematicians in the history of meteorology: the pressure-height problem from Pascal to Laplace», Historia Mathematica, 1, 263-286.

${ }^{43}$ CASsinI, J. (1705), «Reflexions sur les regles de la condensation de l'air», Mém. Acad. Sci., 61-74.
} 
se repetía dejando distintos volúmenes de aire en el tubo. Pero no se encontraron desviaciones significativas de la ley; según comprobó Amontons, ésta todavía se cumplía en una dilatación del aire de más de doscientas veces la del ambiente ${ }^{44}$. En esa ocasión, Gabriel-Philippe de la Hire recordó que, años atrás, su padre había presentado una regla a la Academia que estaba «completamente de acuerdo" con la de Mariotte. Había tomado un resorte en un estado medio de extensión, y al cargarlo con diferentes pesos halló que se extendía en razón directa a los mismos; y al estudiar las compresiones, vio que se hallaban en razón inversa (lo que, dicho sea de paso, justificaba el modelo de aire como "laminillas de resorte») ${ }^{45}$. En fin, tal y como se afirma en la Histoire para ese mismo año de 1705, el tema de la rarefacción y condensación del aire "ha ocupado bastante a la Academia» ${ }^{46}$.

Los resultados eran sorprendentes, puesto que, como se ha dicho, las observaciones ponían de manifiesto que la rarefacción del aire en la cima de las montañas era muy inferior. En la Histoire, Fontenelle expresaba el sentir de muchos: si el aire libre no es diferente del aire encerrado en un tubo de vidrio, entonces el aire de la superficie del suelo debe ser distinto al aire de las montañas ${ }^{47}$.

La Academia todavía tendría una nueva confirmación de esto. Habiendo solicitado a G. Scheuchzer que realizase una prueba en Suiza, éste, en 1710, contrastó la ley de Boyle-Mariotte en siete estaciones situadas a distintas alturas. Las cantidades de aire que introdujo sucesivamente en el tubo iban de 3 a 30 pulg., aumentando 3 pulg. cada vez. El resultado sólo concordó con la teoría en las dilataciones correspondientes a las primeras 3 pulg. de aire. En cantidades de aire superiores, hasta las 18 pulg., la dilatación se acercaba a 1 ó 2 lín. de la calculada. Y desde ahí hasta las 30 pulg., la dilatación obtenida era siempre mayor que la predicha por la ley. La conclusión definitiva fue que las dilataciones seguían una regla distinta ${ }^{48}$. 124

44 Amontons, G. (1705), "Expériences sur la rarefaction de l'air», Mém. Acad. Sci, 119-

45 LA Hire, G. -P. DE (1705), "Sur la condensation et dilatation de l'air», Mém. Acad. Sci., 110-111. En su De potentia restitutiva (1678), R. Hooke había establecido una ley según la cual los cuerpos elásticos tienden a recuperar su estado de extensión natural con una fuerza que es «siempre proporcional a la distancia o espacio a que se han alejado de ella, sea por rarefacción de sus partes una respecto a la otra o por condensación o amontonamiento de esas partes, juntándose más». Cit. en C. Solís (1989), "Introducción», en Robert Hooke. Micrografía, Madrid: Alfaguara, p. 44

46 Fontenelle, B. B. (1705), "Sur la rarefaction et la condensation de l'air», Hist. Acad. Sci., 10-16; p. 10.

47 Fontenelle (1705), p. 15.

48 Maraldi, G. F. (1711), «Nouvelles experiences sur la dilatation de l'air, faites par M. Scheuchzer sur las montagnes des Suisses, avec des réflexions», Mém. Acad. Sci., 156-159. 


\section{LA LEY DE AMONTONS Y LAS INDAGACIONES SOBRE EL AIRE}

Lo que aquí resulta notable es el aparente olvido de los efectos de la temperatura sobre la fuerza de resorte del aire, tanto más cuanto que éstos habían sido puestos muy de manifiesto por Amontons. El mismo Fontenelle, en 1705, parecía haber olvidado por completo la «nueva propiedad del aire» que había anunciado en la Histoire para 1703. Se preguntaba si «el aire que se encuentra desde la superficie de la Tierra hasta lo alto de las montañas no debería ser considerado como una materia heterogénea y desigualmente susceptible de dilatación en diferentes partes, de modo que en sus distintas dilataciones intervendría algún principio diferente que la desigualdad de los pesos, mientras que el aire de la superficie de la Tierra sería perfectamente homogéneo, y no se dilataría ni se condensaría más que según los pesos» ${ }^{49}$.

\section{El aire septentrional y el aire meridional}

Pero, además, tampoco la atmósfera parecía tener la misma constitución en todas las latitudes. Se sabía que el rango de variación del barómetro era mayor en los países septentrionales que en los meridionales, y que en estos últimos, al nivel del mar, el mercurio del barómetro siempre se encontraba más bajo que en Europa ${ }^{50}$. También se había constatado que la refracción horizontal tenía un valor inferior al hallado en latitudes medias ${ }^{51}$. Esto hizo pensar que la altura de la atmósfera era mayor en los polos que en el ecuador ${ }^{52}$. Pero, además de esto, parecía que también era distinta la capacidad de resorte del aire; según relataba Maraldi en 1709, el jesuíta P. Beze repitió años atrás en Malaca las experiencias de Mariotte, hallando que el aire de allí era menos susceptible de dilatación que el aire europeo ${ }^{53}$.

\footnotetext{
49 Fontenelle (1705), p. 15.

50 MARALDI, G. F (1703), «Experiencies du barometre faites sus diverses montagnes de la France», Mém. Acad. Sci., 229-237; pp. 235-36.

51 FonTENelle, B. B. (1706), "Sur les refractions», Hist. Acad. Sci., 101-103; p. 103.

52 Véase, por ejemplo, Maraldi, G. F. (1703), "Experiences du barometre faites sur diverses montagnes de la France», Mém. Acad. Sci., 229-237; en pp. 235-236. Asimismo La HiRE, P. DE (1705), «Observations de la quantité d'eau de plüie qui est tombée à l'Observatoire Royal pendant l'année derniere 1704, avec les hauteurs du Barometre et du Thermometre, et des remarques sur les vents qui ont regné", Mém. Acad. Sci., 1-5; pp. 3-4. Naturalmente, la diferente temperatura entre estas regiones de la Tierra no entraba en consideración.

${ }^{53}$ Maraldi, G. F. (1709), "Comparaison des observations du barometre faites en différens lieux", Mém. Acad. Sci., 233-246. El P. Beze observó en dos días diferentes, uno con cielo despejado y otro con el cielo muy cubierto de nubes. En el primero, con una presión atmosférica de 26 pulg. 6 lín., y el termómetro a $69^{\circ}$ (no se especifica la escala), dejó 3 pulg., y luego 7
} 
Para asegurarse de que este resultado no podía deberse a que, hallándose el aire de Malaca más rarificado por el calor del clima, fuese así menos susceptible de dilatación, Maraldi realizó un experimento ${ }^{54}$. Tomó un tubo con mercurio en el que dejó 3 pulg. de aire, al cual "rarificó» sumergiendo todo el tubo en agua hirviendo, y a continuación lo invirtió en la cubeta de mercurio. Al principio, el mercurio se sostenía a pocas líneas del nivel predicho por la ley de Mariotte en el caso de que el aire no se hubiese rarificado (de modo que la influencia de la temperatura no había resultado muy significativa). Pero fue subiendo a medida que se enfriaba y, cuando se enfrió del todo, la columna de mercurio había subido 1 pulg. 2 lín. más de lo exigido por la ley de Mariotte o, lo que es lo mismo, que con este aire "rarificado», el volumen final resultaba menor de lo predicho por la regla, siendo la diferencia con ésta de aproximadamente la mitad de la diferencia hallada en Malaca; al mismo resultado llegó con 6 y con 9 pulgs. de aire. Maraldi concluyó que el aire de Malaca era menos propenso a dilatarse que el de París. Este resultado, unido a las desviaciones halladas en las montañas, le llevó a concluir «que el aire es heterogéneo en estas diferentes partes, de modo que hay que ser circunspecto a la hora de fundar un sistema general sobre experiencias particulares» 55 .

De modo que no en todas las latitudes, ni en todas las alturas, parecía cumplirse la ley de Mariotte, cuya validez parecía confinada al aire del laboratorio. Pero las cosas todavía podrían ir peor si, en ese mismo laboratorio, los barómetros comenzasen a mostrarse disconformes entre sí. Como efectivamente sucedió.

pulg. 6 lín. de aire en el tubo; en el primer caso, el aire se dilató a 7 pulg. 10 lín. y el mercurio descendió a 20 pulg. 7 lín. ; en el segundo, se dilató a 12 pulg. 5 lín., descendiendo el mercurio a 16 pulg. Maraldi notó que, en la primera observación, había una diferencia con la regla de Mariotte entre los volúmes dilatados calculado y observado de 2 pulg. 1 lín., y de 2 pulg. 8 lín. en la segunda. Sin embargo, no he podido deducir estas cifras, obteniendo 5 pulg. 7 lín. y 6 pulg. 6 lín., respectivamente. La misma dificultad encuentro con las diferencias calculadas para las observaciones del segundo día. En todo caso, las dilataciones que presenta resultan inferiores a las predichas por la teoría.

${ }^{54}$ Aunque Maraldi no dice nada al respecto, pudiera ser que lo que tenía en mente es que, puesto que existe un límite a la dilatación del aire (es decir, a la validez de la ley de Mariotte) a grandes dilataciones, y como cabría pensar que este límite no se alcanza bruscamente, a medida que aumentase la dilatación del aire los resultados debían desviarse cada vez más de lo predicho por la ley. Nótese que Maraldi se está refiriendo a una susceptibilidad a la dilatación producida por una disminución en la presión (lograda a través del experimento con el tubo barométrico), no por un aumento en la temperatura.

55 Ibíd., p. 246. Finaliza señalando que en Cayena, en un paralelo próximo a Malaca, las refracciones astronómicas se han encontrado menores que en Europa, y apunta la necesidad de examinar si existe alguna relación entre la manera en que el aire se dilata en diversos climas, y las diferencias encontradas en las refracciones. 


\section{El extraño caso del barómetro del canciller ${ }^{56}$}

Todo comenzó con un barómetro estropeado perteneciente a un canciller (posiblemente Pontchartrain) que W. Homberg se encargó de reparar. Tras ello, el canciller comprobó asombrado que todas las oscilaciones del nivel del mercurio en el tubo se producían en la porción de las platinas correspondiente al mal tiempo. Consultado Amontons, se cercioró de que el tubo no contenía aire, y de que tampoco era responsable el mercurio, que sustituyó por otro. Pero el barómetro se mostró terco en marcar 18 lín. por debajo de otros barómetros puestos junto a él ${ }^{57}$. En palabras de Fontenelle, el fenómeno «sorprendió mucho a toda la Academia ${ }^{58}$. Inmediatamente se formularon varias hipótesis. Una era que el tubo podía tener alguna «humedad grasa», la cual podía contener aire que se dilataba al producirse el vacío, ocupando entonces la parte superior del tubo. Otra, que el vidrio podría ser de una naturaleza tal que el mercurio corroyese su sustancia, liberando al aire encerrado entre sus intersticios (y, en efecto, quienes sostenían tal idea, examinando el tubo al microscopio, hallaron en el vidrio pequeñas burbujas). Otra más, en fin, que podía existir una materia intermedia entre el éter y el aire, cuyas partículas fuesen de un grosor tal que pudiesen atravesar los poros del vidrio del tubo que, en este caso, serían mayores de lo ordinario; éste era el parecer de Amontons.

Pronto se vio que no se trataba de un caso aislado. Gabriel-Philippe de la Hire, quien había optado por pensar que el efecto se debía al aire común disuelto en el mercurio, hizo notar que la altura del mercurio era distinta en cada uno de los tres barómetros que se empleaban en el Observatorio (la mayor diferencia era de 3,5 lín.). En uno de ellos se había observado que, tras llenar el tubo con mercurio dejando salir todo el aire, y haberlo invertido sumergiendo su extremo en la cubeta, cuando comenzaba a aparecer el vacío en lo alto se veían pequeñas burbujas, casi imperceptibles, de aire, que engrosaban repentinamente e invadían el vacío. Unas estaban entre el mercurio y el tubo, y otras surgían del mercurio mismo. Y. si el tubo se volvía a inclinar de modo que lo ocupase de nuevo el mercurio, las burbujas desaparecían en

\footnotetext{
56 Este apartado recoge, con algunos cambios menores, los acontecimientos relatados en una publicación anterior: SELLÉS, M. A. (1993), «El extraño caso del barómetro del canciller», en E. Bustos, J. Echeverría, E. Pérez Sedeño, y M. I. Sánchez Balsameda (eds), Actas del I Congreso de la Sociedad de Lógica, Metodología y Filosofía de la Ciencia en España, Madrid: UNED, 526-529.

57 Amontons, G. (1705), «De la hauteur du mercure dans les barometres», Mém. Acad. Sci., 229-231.

58 Fontentelle, B. B. (1705), "Sur une irregularité de quelques barometres», Hist. Acad. Sci., 16-21; p. 16.
} 
él ${ }^{59}$. El barómetro no era, pues, un instrumento tan exacto como se hubiese querido creer.

Amontons prosiguió las experiencias. Homberg, y con él algunos miembros de la Academia, pensaban que la causa del comportamiento del barómetro del canciller residía en que, al haber lavado Homberg el tubo con espíritu de vino, pudo quedar algo del mismo entre los poros del vidrio, de donde habría surgido, muy rarificado, al producirse el vacío. Los resultados obtenidos por Amontons fueron ambiguos pues, si bien comprobó que al recargar de mercurio el barómetro la diferencia de altura con los otros había disminuído un tanto, al recargar de nuevo el tubo tras haberlo lavado y secado muy bien, volvió a encontrar 19 lín. de diferencia. Según Homberg, no había eliminado todo el espíritu de vino, lo cual sólo se podría conseguir secando el tubo al fuego. Pero, por otra parte, en tubos que nunca habían sido lavados el nivel del mercurio estaba asimismo más bajo, si bien la diferencia disminuía a medida que se los descargaba y recargaba de mercurio. Y, aunque se debiese al espíritu de vino, a Amontons le parecía inverosímil que éste se redujese a aire (hoy diríamos que se evaporase) en tal cantidad como para producir una fuerza de resorte de 19 lín. de mercurio. Pues al inclinar el tubo para que el mercurio invadiese el vacío, este aire debería ocupar un espacio en el tubo de más de 5 lín., mientras que no se percibía nada ${ }^{60}$. De modo que siguió sosteniendo la idea de la porosidad del vidrio. Y es más, lo comprobó. Empleando un cañón de fusil en vez de un tubo de vidrio, encontró que en él el mercurio se sostenía 52 lín. más bajo, muestra de que sus poros debían ser mayores ${ }^{61}$. En cuanto al ascenso del nivel al descargar y recargar el tubo del barómetro, encontró una explicación en una botellita con mercurio que solía llevar en el bolsillo: con el movimiento, el vidrio se había ensuciado y una parte del mercurio se había reducido a una especie de polvo negro. Así, los poros del tubo del barómetro, con las descargas y recargas, podían haberse ido obs-

\footnotetext{
59 LA HiRE, G. -P. DE (1705), «Remarques sur quelques experiences faites avec plusieurs Barometres, et sur la lumière qui fait un de ceux dont on s'est servi en l'agitant verticalement», Mém. Acad. Sci., 226-228. Observó asimismo en los tres barómetros que, cuanto más largo era el tubo (y quedaba por tanto mayor porción de vacío en lo alto), más bajo era el nivel del mercurio, lo que le hizo pensar que el efecto se debía al aire purgado de la porción de mercurio que, antes de invertir el tubo, ocupaba en éste el lugar que después ocuparía el vacío; en consecuencia, sugirió que se adoptase en los tubos de los barómetros una longitud proporcionada al lugar en donde se fuesen a situar, de modo que la porción de vacío fuese siempre de 1 pulg.

${ }^{60}$ La idea de que el vapor se condensase al inclinar el tubo no se les podía ocurrir entonces.

${ }^{61}$ Middleton, W. E. K. (1964), The History of the Barometer, Baltimore: The Johns Hopkins Press, p. 157, sospecha que el efecto se debió a la liberación del gas adsorbido en el tubo de hierro.
} 
truyendo con esta "grasa y parte plúmbea del mercurio», tornándose cada vez más impermeables a las partes menores del aire. El lavado del tubo con espíritu de vino eliminaría esta obstrucción. Opinión que acabaría por compartir G. P. de la Hire ${ }^{62}$.

El fallecimiento de Amontons en octubre de 1705 interrumpió sus experiencias. Poco después, Maraldi presentó otras nuevas en apoyo de las ideas de Homberg. Comprobó que la altura del mercurio descendía después de haber lavado un tubo con espíritu de vino y que, cuanto más tiempo se dejase secar, menor era el descenso, hasta desaparecer por completo si el tubo se dejaba secar durante varios días. También probó a lavarlos con «agua de vida" y agua común. Con "agua de vida», el descenso del mercurio era menor que con espíritu de vino, y con agua común era todavía más pequeño. Como estos descensos no seguían la proporción de los pesos específicos, sino todo lo contrario, concluyó que el efecto no se debía a que estos líquidos se rarificasen en el vacío, sino al desprendimiento del aire disuelto en ellos (nótese la influencia del modelo hidrostático, según el cual el resorte aumenta con el peso). De todas formas, y tal como se apuntaba en la misma Histoire de la Academia en que se relataban estos resultados, el problema todavía no se podía dar por resuelto ${ }^{63}$. (Tan sólo desaparecería cuando, a partir del primer cuarto de siglo, la práctica de hervir el mercurio en el tubo del barómetro produjese su secado y desprendiese las burbujas de aire contenidas en el mercurio).

\section{La ley de Amontons y el aire húmedo}

Si la ley de Mariotte, la fiabilidad de los barómetros y la misma homogeneidad del aire estaban en entredicho, la nueva propiedad descubierta por Amontons no podía escapar indemne. En 1708, G. P. de la Hire le reprochaba haber extendido al aire a la presión atmosférica usual su resultado sobre la dilatación por el calor del agua hirviendo, que había obtenido con aire por encima de su compresión natural, "pues en todas estas conclusiones hay que servirse necesariamente de varias suposiciones sobre la naturaleza del aire, del cual no podemos asegurar que tengamos un conocimiento muy perfec-

\footnotetext{
62 Amontons, G. (1705), «Suite des remarques sur la hauteur du mercure dans les barometres», Mém. Acad. Sci., 232-236 y 267-272. LA HIRE, G. -P. DE (1706), «Observations de la quantité d'eau de pluïe qui est tombée à l'Observatoire pendant l'année derniere 1705, et de la hauteur du Thermometre et du Barometre», Mém. Acad. Sci., 1-6; p. 5.

${ }^{63}$ Fontenelle, B. B. (1706), "Sur une irregularité de quelques Barometres», Hist. Acad. Sci., $1-3$
} 
to» ${ }^{64}$. De modo que repitió la experiencia con aire a la presión atmosférica. Para ello empleó un tubo curvado como el de la fig. 2, en que el mercurio se sostenía a la misma altura en las dos ramas (el pequeño tubo EF servía para dejar salir el aire a medida que se vertía el mercurio por A, y se sellaba cuando se terminaba de verter). Lo metió en agua hirviendo, y registró la elevación del mercurio en el tubo AB. Esto lo verificó en dos ocasiones, una con la presión atmosférica a 27 pulg. 7,5 lín., en que ascendió 9 pulg. 2,5 lín.; y otra con la presión a 28 pulg. 5 lín., en que ascendió a 8 pulg. En ambos casos el ascenso resultaba menor que la tercera parte de la presión atmosférica. Es más, en la segunda experiencia hacía más frío, el aire estaba más pesado, y por tanto el recipiente contenía más de sus "partículas a resorte» en un mismo volumen, y con todo la elevación del nivel del mercurio era menor, cuando cabría esperar lo contrario.

Pasó a continuación a comprobar que el volumen del aire encerrado en el recipiente no tenía ninguna influencia. Para ello tomó un tubo como el de la fig. 4, en que el aire estaba cargado con la altura de mercurio EF. Si ahora se cortaba la comunicación en $\mathrm{B}$, la altura del mercurio no variaba.

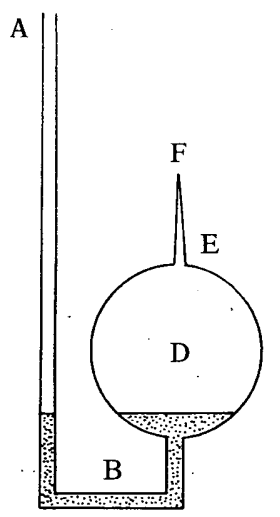

Fig. 2

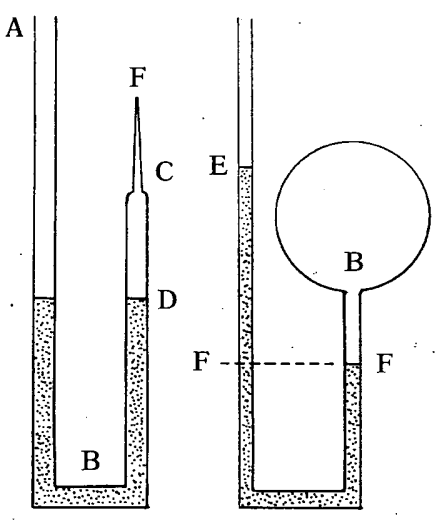

Fig. 3

Fig. 4

${ }^{64}$ LA HIRE, P. DE (1708), «Expériences et remarques sur la dilatation de l'air par l'eau boüillante», Mém. Acad. Sci., 274-288; p. 275. 


\section{LA LEY DE AMONTONS Y LAS INDAGACIONES SOBRE EL AIRE}

Las sospechas recayeron, no en la calidad de los resultados experimentales de Amontons, sino en la de la ley de Mariotte, de la que se había servido aquél. Argumentaba que, como se sabía que los resortes no tienen una compresión ni una extensión infinitas, y que ambas debían tener sus límites, en rigor estos resortes no debían seguir la razón de las cargas que los comprimen, incluso para un cambio de carga pequeño. Además, todavía cabía sospechar en el aire alguna propiedad particular desconocida. Y para tratar de averiguar algo realizó un nuevo experimento. Tomó un tubo curvado como el de la fig. 3 , con una de sus ramas rematada por un capilar CF. El diámetro interior del tubo era de 3 lín., y por tanto su capacidad era muy inferior a la del recipiente D de la experiencia anterior, que tenía 2 pulgs. de diámetro. Vertió el mercurio, dejó 3 pulg. de aire desde $\mathrm{C}$ hasta $\mathrm{D}$, selló el extremo $\mathrm{F}$ e introdujo el tubo en agua hirviendo. Siendo la presión atmosférica de 28 pulg. 3 lín., encontró una diferencia en el nivel del mercurio de 3 pulg. 5 lín. Dado que aquí la dilatación había cambiado sensiblemente el volumen del aire encerrado, aplicó la ley de Mariotte y encontró que, para reducirlo a su volumen inicial, se habrían tenido que añadir más de 21 pulg. de mercurio. De aquí se seguía que una pequeña cantidad de aire dilatado por el agua hirviendo realiza más esfuerzo que una mayor.

Otros también habían realizado experiencias que refutaban los resultados de Amontons. En las Mémoires de Trévoux de octubre de 1705, L. Nuguet publicó tres experimentos cuyo resultado arrojaba una relación entre el aire dilatado y el natural de 16 a 1 . La Hire, comentando estas experiencias, hizo notar que Nuguet había llenado de agua el recipiente para determinar su volumen antes de meterlo en agua hirviendo para dilatar el aire. La Hire piensa que el poco de agua que pudo quedar, «elevándose entonces en partículas que se ponen en muy gran movimiento por el calor, [éstas] hubiesen podido extender no solamente los resortes del aire, sino incluso, ocupando un volumen muy grande, habrían arrastrado y empujado al salir fuera del frasquito casi todo el aire que allí estaba contenido», al modo en que sucede en las eolipilas, de modo que en el recipiente de Nuguet habría quedado muy poco aire natural.

Estos efectos de la humedad podían explicar la disparidad de los resultados. Amontons había realizado su experiencia al mismo tiempo con distintos recipientes, es decir, con el mismo aire; mas si las pruebas se efectúan en días distintós, con aire de distinto grado de humedad, esto afectará a los resultados. Esto lo confirma repitiendo el experimento con un recipiente seco, y luego con el mismo conteniendo un poco de agua. La dilatación, en el segundo caso, resultó ocho veces mayor que en el primero. A este misma conclusión había llegado también Stancari, un matemático de Bolonia correspondiente de Cassini en la Academia ${ }^{65}$. Usó un tubo similar a los

${ }^{65}$ Fontenelle, B. B. (1708), «Sur la dilatation de l’air», Hist. Acad. Sci., 11-19; pp. 12-13. 


\section{MANUEL SELLES GARCIA}

empleados por Amontons (fig. 1), que sumergió en agua hirviendo para rarificar el aire que contenía. Hecho esto, cerraba el tubo y lo sumergía en agua fría, dejando entrar al agua, reduciéndose el aire anteriormente dilatado a un pequeño volumen que quedaba encerrado en la bola. Stancari encontró siempre que, cuando el tubo había estado húmedo en su interior antes de realizar la experiencia, el volumen de aire que quedaba finalmente en la bola era menor; o, lo que es lo mismo, que el aire húmedo se había rarificado por el calor más que el seco. «El efecto de la humedad es tan grande, que apenas es creíble», concluía Fontenelle tras relatar estos experimentos. Stancari había soplado en un tubo y comprobado que la sola humedad de su aliento había hecho sostener al aire 6 pulg. de mercurio más que hallándose seco. Un resultado que favorecía la hipótesis de Homberg sobre lo acaecido con el barómetro del canciller, y que mostraba que el termómetro de Amontons no podía ser universal.

Retomando lo que dijo en la Histoire de 1705, Fontenelle encuentra ahora en la humedad la causa de las disparidades con la ley de Mariotte que se habían encontrado en lo alto de las montañas. Opina que la fuente de heterogeneidad del aire libre se halla en el desigual reparto de los vapores acuosos, más abundantes en lo alto de las montañas, donde se reúnen para formar las lluvias. Allí se encuentra que posee una mayor fuerza elástica. En el laboratorio, donde las pruebas se efectúan con el mismo aire, igualmente húmedo en toda su extensión, se observan los resultados de Mariotte. Eso mismo había comprobado Parent, hallando que, aunque la ley se cumplía con suficiente aproximación, estba sometida a ciertas variaciones. Estas variaciones, según Parent, serían como las ordenadas de una curva que irían disminuyendo al principio, en seguida se tornarían iguales, aumentarían, se volverían a tornar iguales, y terminarían por volver a disminuír.

Cuando la elasticidad del aire parece desviarse del comportamiento de los resortes, hay que dudar de la existencia de los mismos. Para Parent, las partes del aire «no son ni láminas plegadas que se abren, ni espiras que se desenrrollan, ni nada equivalente ${ }^{66}$. Se trata de simples moléculas flotando en el éter sutil y siempre muy agitado. Están tanto más separadas entre sí, y tienden tanto más a separarse, cuanto más abundante es y con mayor rapidez se mueve la materia etérea que llena sus intervalos. Así, cuando la dilatación del aire es pequeña, su proporción es menor que la de los pesos, porque el poco de materia etérea que ha entrado entre sus intervalos no puede ejercer todo su efecto, cosa que va logrando a mayores dilataciones, llegando a una proporción mayor que la de los pesos. Pero cuando la dilatación es grande, esta materia se halla en tan gran cantidad que puede tornar a las partículas de aire capaces de penetrar la superficie del mercurio, reduciendo así su capacidad

${ }^{66}$ Ibid., p. 17. 


\section{LA LEY DE AMONTONS Y LAS INDAGACIONES SOBRE EL AIRE}

de comprimirla. Para comprobarlo, tomó una serie de pequeñas redomas, puso en cada una una pequeña cantidad de distintos líquidos, extrajo el aire, y las selló. Dispuso una serie análoga en la que no se había extraído el aire, sellándolas asimismo. Y las puso sobre carbones encendidos. El resultado fue sorprendente. Aquéllas que contenían aire, que al calentarse hubiese debido hacerlas estallar por la fuerza de su resorte, sólo se fundieron por la parte en contacto con las brasas, escapando el aire por la abertura producida. Las otras, las que no contenían aire, estallaron con fuerte detonación. Parece que la materia etérea introducida por el fuego en las redomas no podía hacer contra sus paredes un esfuerzo tan grande por medio de las «sutiles y delicadas» partículas de aire como mediante las partículas más masivas de los distintos líquidos. De ahí que la humedad aumentase en tan alto grado la fuerza elástica del aire.

Como es de suponer, el experimento de Parent también fue repetido. Carré, poco después, obtuvo un resultado dispar, y esto despejó un tanto las dudas sobre el resorte del aire ${ }^{67}$. Pero parece que a esas alturas el esfuerzo experimental se había agotado. Según escribiría Carré, «las menores experiencias pueden embarazar a menudo al espíritu de un físico, que no admite otra fuerza ni otra virtud en los cuerpos que aquélla que procede del movimiento y figura de sus partes. Pero aunque a menudo no se haga otra cosa que adivinar, queriendo explicar algunos efectos o algunas experiencias particulares, no se deja de reconocer que es un sentimiento verdaderamente ridículo el de pretender establecer un pirronismo absoluto en la Física, y que en esta ciencia, al igual que en varias otras, se está reducido a la siguiente proposición, que se ha llegado a conocer que nada se puede saber $"{ }^{68}$. Así, no obstante, debió parecerles a los físicos experimentales franceses de principios del setecientos.

\section{Conclusión}

Desde un punto de vista histórico, la lección que finalmente se extrajo de todo este cúmulo de observaciones y experiencias fue positiva, pues se puso de manifiesto la gran influencia de la temperatura y la humedad sobre la elasticidad del aire. Por su parte, la hipsometría barométrica adquirió consciencia de que para tratar con la atmósfera no se podía trasladar a ésta un modelo puramente hidrostático, y que los factores antes mencionados (en suma, las condiciones meteorológicas) podían influír notablemente en el resultado de sus mediciones.

${ }^{67}$ Carré, L. (1710), «Experiences sur le ressort de l'air», Mém. Acad. Sci., 1-7.

${ }^{68}$ Ibid., p. 6. 
Sabido esto, el paso siguiente - visto retrospectivamente - hubiese debido ser la búsqueda de resultados cuantitativos: la determinación precisa de los efectos de la temperatura y la humedad sobre la presión del aire y de la atmósfera. Más que a la falta de una buena práctica experimental, creo que su ausencia se debió, por un lado, a las carencias teóricas; por otro, a la incapacidad en la época de desarrollar instrumentos de medida apropiados; y, finalmente, a la índole de los objetivos buscados.

Como es sabido, el corpuscularismo mecanicista del momento proveía de un marco explicativo a posteriori; no daba lugar a la formulación de modelos matematizados que fuesen predictivos y, por consiguiente, cuantitativamente contrastables. Para empezar, la formulación de tales modelos - si es que se quería ir más allá del puro ejercicio matemático- demandaba, si no un cierto conocimiento, sí cuando menos una toma de decisiones respecto de la naturaleza que habría que atribuír a sus componentes físicos. Y esto no parecía sencillo. En el caso del aire, considerado en un inalcanzable estado de pureza, estaba en suspenso la cuestión de si sus partes eran todas iguales, o tenían distinto tamaño (con la posibilidad de que se escurriese por los poros de los recipientes, cuya constitución y tamaño resultaban igualmente desconocidos). En el caso de la atmósfera, ésta se creía constituída, tradicionalmente, por aire, vapores y exhalaciones, y quedaba abierto el interrogante de cuál era la constitución de los mismos, y si a ellos se podía sumar algún fluido sutil de propiedades ignoradas. Además, en conjunto, se convenía en la heterogeneidad de tal constitución en función de la altura, de la posición geográfica, o del tiempo atmosférico. De modo que los hechos positivos encontrados. (ley de Boyle-Mariotte, ley de Amontons, incremento del resorte del aire con la humedad) sólo se podían suponer válidos a escala local (en el espacio y en el tiempo), como se veía cada vez que se obtenían resultados dispares al repetir una experiencia.

Sin embargo, existía un modelo. Junto a este marco de explicación mecanicista coexistía (pero no se vertebraba con él) otro marco teórico que, procedente de la tradición matemática clásica, tenía unas características muy distintas: la hidrostática ${ }^{69}$. La experiencia de Torricelli y la idea del «mar de aire» tuvieron como consecuencia inmediata la adopción para la atmósfera del modelo hidrostático, así como la conceptualización de un instrumento, el

\footnotetext{
${ }^{69}$ Recuérdese en este punto la distinción que señaló Kuhn en 1976 entre "ciencias clásicas" $\mathrm{y}$ «ciencias baconianas», con su afirmación de que la relación entre ambos tipos de ciencia fue escasa en el siglo XVIII y que, cuando se dio, estuvo erizada de dificultades. Este es uno de tales casos. KUHN, T. S. (1976), «Mathematical versus Experimental Traditions in the Development of Physical Science», Journal of Interdisciplinary History, 7, 1-31. Una versión revisada en Kunn, T. S. (1977), The Essential Tension, Chicago, The University of Chicago Press, y traducido al español en KuHN, T. S. (1983), La tensión esencial, México, F. C. E., pp. 56-90.
} 


\section{LA LEY DE AMONTONS Y LAS INDAGACIONES SOBRE EL AIRE}

barómetro, cuyo principio de funcionamiento se explicaba por las leyes del equilibrio y la balanza ${ }^{70}$. Este maridaje entre dos tradiciones científicas distintas constituyó, al principio, todo un éxito, como lo muestran la experiencia del Puy-de-Dôme y la obra de Pascal, la ley de Boyle y la derivación por Halley de la ley hiperbólica del decrecimiento de la presión con la altura, que abrieron el camino a la hipsometría barométrica. Pero los problemas, como se ha visto, no tardaron en presentarse. Por un lado, la compresibilidad del aire lo situaba en una categoría completamente distinta a la del agua incompresible (así por ejemplo, como se ha visto, si un "mar de agua" posee una superficie definida, parecía que tal cosa no podía suceder con el «mar de aire»). Por otro lado, si el agua resultaba un elemento bastante puro, y por consiguiente constante en sus propiedades, no sucedía así con el aire atmosférico: como se ha dicho, de acuerdo con las viejas enseñanzas aristotélicas todavía imperantes, tal aire estaba mezclado con vapores y exhalaciones en diversa proporción según las circunstancias, y que podían modificar diversamente tanto su peso como la fuerza de su resorte; este es el caso del aire húmedo. A esto deben añadirse los efectos de la temperatura, cuyas primeras regularidades fueron puestas de manifiesto por Amontons. Finalmente, se trataba de acomodar por la fuerza un sistema físico notoriamente dinámico, como lo es la atmósfera, a un modelo estático que se sabía impropio (nadie, por ejemplo, podía negar la existencia de vientos).

Por otra parte, los resultados dispares pueden achacarse a la desigual pericia de los experimentadores, a las escasamente controladas condiciones del experimento y a la poca fiabilidad de los instrumentos, pero esta afirmación parece un tanto anacrónica si se toma en consideración que el mecanicismo no podía constituir un marco que suministrase una teoría del instrumento y apuntase las condiciones que debían ser controladas. Sin embargo, gracias a Amontons y al barómetro del canciller se impuso la necesidad de registrar no sólo la presión, sino también la temperatura y la humedad, cada vez que se realizaba una prueba. Aunque ni los termómetros eran comparables (dejemos de lado la cuestión de su precisión), ni se había dado con un medio viable para cuantificar el grado de humedad del aire. De modo que no parecía haber forma de cuantificar la influencia de esas condiciones que se anotaban.

Resta la índole de los objetivos. A la hipsometría barométrica no le interesaba por sí misma la diversidad de.constitución de la atmósfera con la altura: buscaba una regla práctica que funcionase a la hora de medir alturas de montañas para reducir una triangulación geodésica al nivel del mar, algo que

\footnotetext{
${ }^{70}$ Cabe señalar aquí que esto, en más de un estudioso, originó una confusión entre el peso del aire y su fuerza de resorte.
} 
no pudo lograr hasta que se introdujeron en las fórmulas las correcciones adecuadas para la temperatura ${ }^{71}$. Amontons, en su primera memoria, no se mostraba interesado en investigar los efectos de la temperatura sobre el resorte del aire, sólo en demostrar que su «molino de fuego» podía funcionar. En la segunda, buscaba un termómetro "universal» respecto del cual se pudiesen calibrar termómetros comparables; no era su objetivo el descubrir «una nueva propiedad del aire». El aire atmosférico, por sí mismo, no parecía constituír un foco de especial interés; ni tan siquiera para esos meteorólogos que registraban pacientemente día tras día las condiciones atmosféricas, pues más que la causa de los fenómenos, lo que buscaban - desesperando cada vez más de hallarlas- eran sus regularidades.

A ello habría que unir, finalmente, ese baconianismo escéptico que parecía dominar por entonces las investigaciones de los académicos franceses. Se valoraban las invenciones útiles y el hallazgo de regularidades muy por encima de la formación de sistemas. Se pensaba que la curiosidad intelectual debía quedar saciada casi con cualquier configuración de las formas y movimiento de las partículas, y que dicha curiosidad no debía conducir todavía a la formación de sistemas (el caso de Haubskee parece señalar que, al otro lado del Canal, ni tan siquiera se consideraba esa posibilidad). Como escribía Fontenelle, «para las verdades de Física hay una cierta madurez, que sólo el tiempo les puede dar ${ }^{72}$. Sin embargo, se desesperaba de que la colección de datos reunida por medio de la observación y el experimento pudiese ser sistematizada alguna vez; se desesperaba, en el fondo, de que la naturaleza o, cuando menos, algunas de sus partes, llegasen a ser asequibles a la filosofía natural ${ }^{73}$. Tal fuerza debió cobrar esta convicción, que se renunció a la inducción de las mismas leyes obtenidas por la observación y el experimento, en este caso las de Mariotte y Amontons. No se trataba tanto de la falta de pericia experimental o de la ausencia de una teoría de errores, como del exagerado respeto a unos resultados de la observación que nadie parecía estar dispuesto a poner en duda para intentar salvar las leyes que se inducían de los mismos.

\footnotetext{
71 Sólo después de haber hallado disparidades entre las predicciones y las medidas, éstas se emplearon para contrastar la validez de la ley de Boyle.

72 Fontenelle (1708), p. 19.

73 Estas mismas actitudes se manifiestan el el campo de las ciencias de la vida. Véase Roger, J. (1963), Les sciences de la vie dans la pensée française du XVIIIe siècle, París, Armand Colin, pp. 444 ss. Roger señala que, por falta de concebir una ciencia positiva (una ciencia que se limite a los fenómenos, pero que los reúna para extraer leyes), el pensamiento científico del momento se halla sometido todavía a la vieja alternativa del racionalismo dogmático, con el que se confundirá el deseo de razonar, y el escepticismo observador, que triunfará sobre el anterior sin saber integrar la observación en una teoría equilibrada del conocimiento. (Vid. pp. 451-52).
} 